\title{
bcl Morphology Formation Strategy on Nanostructured Titania via Alkaline Hydrothermal Treatment
}

\author{
Fry V. Steky ${ }^{1}$, Veinardi Suendo, ${ }^{1,2 *}$, Rino R. Mukti1,2, Didi P. Benu ${ }^{1,3}$, Muhammad Reza1, \\ Damar R. Adhika ${ }^{2}$, Viny V. Tanuwijaya ${ }^{2}$, Ashari B. Nugraha ${ }^{2}$
}

${ }^{1}$ Division of Inorganic and Physical Chemistry, Faculty of Mathematics and Natural Sciences, Institut Teknologi Bandung, Jl. Ganesha No. 10, Bandung 40132 Indonesia

${ }_{2}^{2}$ Research Center for Nanosciences and Nanotechnology, Institut Teknologi Bandung, $\mathrm{Jl}$. Ganesha No 10, Bandung 40132, Indonesia

${ }^{3}$ Department of Chemistry, Universitas Timor, Jl. Eltari, Kefamenanu 85613, Indonesia

Received: $7^{\text {th }}$ December 2018; Revised: 27th March 2019; Accepted: $10^{\text {th }}$ April 2019; Available online: 30th September 2019; Published regularly: December 2019

\begin{abstract}
Titanium dioxide $\left(\mathrm{TiO}_{2}\right)$ is a semiconductor material that plays an important role in photocatalysis. Bicontinuous concentric lamellar $(b c l)$ is an interesting morphology with an open channel pore structure that has been successfully synthesized on silica-based materials. If $b c l$ morphology can be applied in $\mathrm{TiO}_{2}$ system, then many surface properties of $\mathrm{TiO}_{2}$ can be enhanced, i.e. photocatalytic activity. A simple and effective strategy has been demonstrated to transform aggregated and spherical $\mathrm{TiO}_{2}$ particles to $b c l$ morphology via alkaline hydrothermal route. Alkaline hydrothermal treatment successfully transforms $\mathrm{TiO}_{2}$ particle surface to have $b c l$ morphology through swelling with ammonia then followed by phase segregation process. We proposed this strategy as a general pathway to transform the particle surface with any shape to have $b c l$ morphology. Copyright (C) 2019 BCREC Group. All rights reserved
\end{abstract}

Keywords: Alkaline hydrothermal treatment; bcl morphology; lamellar morphology; modified morphology; nanostructured $\mathrm{TiO}_{2}$

How to Cite: Steky, F.V., Suendo, V., Mukti, R.R., Benu, D.P., Reza, M., Adhika, D.R., Tanuwijaya, V.V., Nugraha, A.B. (2019). bcl Morphology Formation Strategy on Nanostructured Titania via Alkaline Hydrothermal Treatment. Bulletin of Chemical Reaction Engineering \& Catalysis, 14(3): 513-520 (doi:10.9767/bcrec.14.3.3853.513-520)

Permalink/DOI: https://doi.org/10.9767/bcrec.14.3.3853.513-520

\section{Introduction}

Titanium dioxide $\left(\mathrm{TiO}_{2}\right)$ is an important inorganic semiconductor material in various applications due to its photosensitive, photostable, and environmentally friendly properties [1]. The advantages properties of $\mathrm{TiO}_{2}$ provide potential applications in many fields such as photocatalysts [2], dye-sensitized solar cells [3], and cata-

*Corresponding Author.

E-mail: vsuendo@chem.itb.ac.id (V. Suendo)

Phone: +62-22-2502103, Fax: +62-22-2504154 lyst support [4]. Due to its wide application, research about synthesis, characterization and fundamental understanding of $\mathrm{TiO}_{2}$ material has been intensively studied in last recent years. Many researchers developed $\mathrm{TiO}_{2}$ synthesis methods to enhance the $\mathrm{TiO}_{2}$ activity in various applications [5,6], especially as photocatalysts.

Many research groups reported that particle size and morphology are important to obtain $\mathrm{TiO}_{2}$ with good photocatalytic activity [7-9]. The effective charge transfer in photocatalyst $\mathrm{TiO}_{2}$ requires the presence of surface active sites [10]. 
Have a high surface area is the essential requirement to have high surface-active sites photocatalyst. The common strategy to increase surface area is by reducing the crystallite size. However, small $\mathrm{TiO}_{2}$ particles have low mechanical strength and easily agglomerate to form larger particles. We can use another strategy to increase the surface area of $\mathrm{TiO}_{2}$ particles by modifying its morphology. Conventional mesoporous $\mathrm{TiO}_{2}$ has only closed channel pore structure from intercrystallite spaces. However, closed channel pore structure has several drawbacks, such low accessibility due to diffusion limitation, pore blocking, and difficult pore surface activation, despite its high selectivity. Therefore, in vast reaction schemes, the open channel is more favorable. $\mathrm{TiO}_{2}$ particles with open channel structure provide high surface area, high accessibility and facile pore surface modification [11]. Photocatalytic activity of mesoporous materials with open channel pore structure is easy to adjust chemically due to large reachable surfaces [12].

One of morphology with an open channel pore structure that attracts much attention is bicontinuous concentric lamellar ( $b c l$ ) morphology. bcl morphology has been successfully synthesized in various type silica-based materials using reverse micelle templating method [13]. The morphology of $b c l$ silica is quite unique. Here, uniform spherical particles consist of bicontinuous lamellae arranged concentrically providing high surface area, large pore volume, and high accessibility [13]. If this morphology can be applied in $\mathrm{TiO}_{2}$ system, then many surface properties of $\mathrm{TiO}_{2}$ can be enhanced, i.e. photocatalytic activity. Synthesis of $\mathrm{TiO}_{2}$ with reverse micelle has been reported elsewhere, but only $\mathrm{TiO}_{2}$ particles with irregular morphology obtain in the form of aggregates. This type of particles provides low photocatalytic activity [14]. bcl morphology cannot be obtained using the reverse micelle templating due to the hydrolysis nature of $\mathrm{TiO}_{2}$ precursors, i.e. $\mathrm{TiCl}_{4}$, TTIP, etc. It is a rule of thumb that $\mathrm{TiO}_{2}$ precursors hydrolysis rapidly event in the traces of water.

Herein, we demonstrate the transformation of aggregated and spherical $\mathrm{TiO}_{2}$ particles to bcl morphology via alkaline hydrothermal treatment. Synthesis of nanostructured $\mathrm{TiO}_{2}$ with $b c l$ morphology will be carried out in two simple steps without surfactant. Slow hydrolysis is the main strategy to form $\mathrm{TiO}_{2}$ particles with controllable particle shape. Swelling and phase segregation is the key to obtain bicontinuous lamellar morphology.

\section{Materials and Methods}

2.1 Preparation of Nanostructured $\mathrm{TiO}_{2}$ with bcl Morphology

Titanium dioxide was synthesized by modifying previously reported method [5]. First, 1.1 $\mathrm{mL}$ of Titanium (IV) isopropoxide (TTIP, 99\%, Sigma-Aldrich) was added to $100 \mathrm{~mL}$ of ethanol (99\%, Merck) under vigorous stirring for 30 minutes until milky white suspension formed. It was kept static for 12 hours and then filtered. The powder obtained was washed with deionized (DI) water and ethanol, and dried at $60{ }^{\circ} \mathrm{C}$ for 6 hours. Then, $0.3 \mathrm{~g}$ of as-prepared $\mathrm{TiO}_{2}$ was dissolved in $24 \mathrm{~mL}$ of ammonia $(25 \%$, Sigma-Aldrich) together with $12 \mathrm{~mL}$ of DI water. The mixture was transferred to a $50 \mathrm{~mL}$ Teflon-line stainless steel autoclave and heated to $120{ }^{\circ} \mathrm{C}$ for 6 hours. After that, the autoclave was cooled down to room temperature naturally. The obtained products were filtered and washed with DI water and ethanol. Finally, the powder obtained was calcined at $500{ }^{\circ} \mathrm{C}$ for 1 hour. All the steps above are repeated using the same method with absolute ethanol is replaced by DI water.

Within this study, the samples are designated as $\mathrm{TiO}_{2}$-A (aggregated as-synthesized), $\mathrm{TiO}_{2}$ $\mathrm{S}$ (spherical as-synthesized), $\mathrm{TiO}_{2}$-A-HT (aggregated after hydrothermal treatment), $\mathrm{TiO}_{2}$-S-HT (spherical after hydrothermal treatment), $\mathrm{TiO}_{2}$-A-HT-500 (aggregated after hydrothermal treatment and calcination at $500{ }^{\circ} \mathrm{C}$ ), and $\mathrm{TiO}_{2}$-S-HT-500 (spherical after hydrothermal treatment and calcination at $500{ }^{\circ} \mathrm{C}$ ).

\subsection{Sample Characterizations}

The morphology of obtained samples was characterized with scanning electron microscopy (SEM, Hitachi SU3500) with the accelerating voltage at $10 \mathrm{kV}$. The phase structures were determined by Raman spectroscopy (Bruker - Senterra) with a 532 nm Nd:YAG DPSS (diode-pumped solid-state) laser at 2 $\mathrm{mW}$ on $5 \mathrm{~s}$ scanning time and X-ray diffraction (XRD, Bruker D8 Advance with LynxEye XE detector) on a Scintag diffractometer with CuKa1 radiation $(\lambda=1.54060 \AA)$ at a scanning rate of $0.239^{\circ} \mathrm{s}^{-1}$ in the $2 \theta$ range from 10 to $90^{\circ}$. Photoluminescence signals were measured by a UV-visible fiber spectrometer (USB4000 Ocean optics) coupled to a $120 \mathrm{x}$ magnification microscope objective lens equipped with a 405 $\mathrm{nm}$ long-wave pass edge filter (Semrock EdgeBasic, BLP01-405R-25). The sample was excited by a $405 \mathrm{~nm}$ diode laser equipped with a 405 $\mathrm{nm}$ laser clean-up filter (Semrock MaxLine, 
LL01-405-12.5) and a focusing lens setup. $\mathrm{N}_{2}$ physisorption were carried out using a Quantachrome NOVAtouch $\mathrm{LX}^{4}$.

\section{Results and Discussion}

Nanostructured $\mathrm{TiO}_{2}$ with bcl morphology was prepared as explained in the Experimental Section. As shown in Figure 1a and 1b, the aggregate and spherical shape particles were investigated by SEM. The main difference in preparation condition between two kinds of resulted particles is the hydrolysis rate of $\mathrm{TiO}_{2}$ precursor. TTIP dissolved in DI water experiences rapid hydrolysis, thus produces aggregated particles with an irregular shape. On the other hand, if DI water was replaced by ethanol, TTIP experiences a slow hydrolysis pathway to producing spherical particles.

Figure 1c and 1d show the morphology of particles after alkaline hydrothermal treatment. We observed the surface of both aggregates and spherical particles transform into bicontinuous lamellar morphology. Alkaline hydrothermal treatment has been proved to be independent of particle shape and synthesis history. If the particles have not been calcined yet, then the method can be applied.

Based on results above, we hypothesized that the formation of these lamellar structures was carried out by chemically modifying the surface of particles through swelling and phase

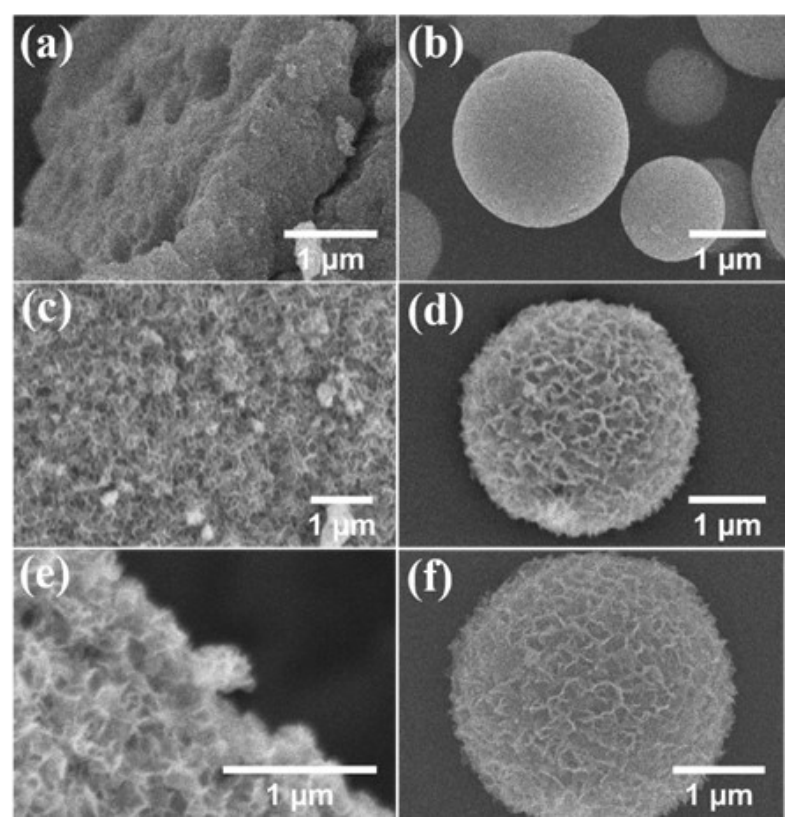

Figure 1. SEM images of nanostructured $\mathrm{TiO}_{2}$ obtained after different processes: (a) $\mathrm{TiO}_{2}-\mathrm{A}$, (b) $\mathrm{TiO}_{2}-\mathrm{S}$, (c) $\mathrm{TiO}_{2}-\mathrm{A}-\mathrm{HT}$, (d) $\mathrm{TiO}_{2}-\mathrm{S}-\mathrm{HT}$, (e) $\mathrm{TiO}_{2}$-A-HT-500 and (f) $\mathrm{TiO}_{2}$-S-HT-500. segregation under alkaline condition. Figure 1e and 1f show the SEM images of samples after calcination at $500{ }^{\circ} \mathrm{C}$ for $6 \mathrm{~h}$. Both images show no significant changes in their morphology after calcination process with respect to Figure $1 \mathrm{c}$ and $1 \mathrm{~d}$, respectively. Although SEM images do not show noticeable morphology changes after the calcination process, Raman, XRD, and BET analysis reveal significant differences.

Figure 2a shows Raman spectra of synthesized $\mathrm{TiO}_{2}$ samples. In principle, Raman analysis is not a sensitive method to distinguish particle morphology, i.e. both uncalcined aggregated and spherical particles give relatively similar Raman spectra. However, Raman is very sensitive to distinguish different chemical components and polymorphism in crystalline materials, i.e. between anatase and rutile $\mathrm{TiO}_{2}$ polymorphs.

In sample $\mathrm{TiO}_{2}-\mathrm{A}$ and $\mathrm{TiO}_{2}-\mathrm{S}$ shows broad bands at 200, 450, and $610 \mathrm{~cm}^{-1}$. These peaks were frequently observed in amorphous $\mathrm{TiO}_{2}$ [15]. In sample $\mathrm{TiO}_{2}-\mathrm{A}-\mathrm{HT}$ and $\mathrm{TiO}_{2}$-S-HT, the peaks are seen at 190, 270, 440, and $650 \mathrm{~cm}^{-1}$. These peaks due to the formation of titanate species during alkaline hydrothermal process [15]. Moreover, aggregated particles $\left(\mathrm{TiO}_{2}-\mathrm{A}\right.$ HT) provide spectra with richer features and sharper peaks with respect to spherical particles $\left(\mathrm{TiO}_{2}-\mathrm{S}-\mathrm{HT}\right)$. This might due the aggregated particles have more defects on their surfaces, which is in good agreement with SEM results depicted in Figure 1c and 1d, respectively.

After calcined samples demonstrate typical anatase peaks with Raman shift at 154.50,

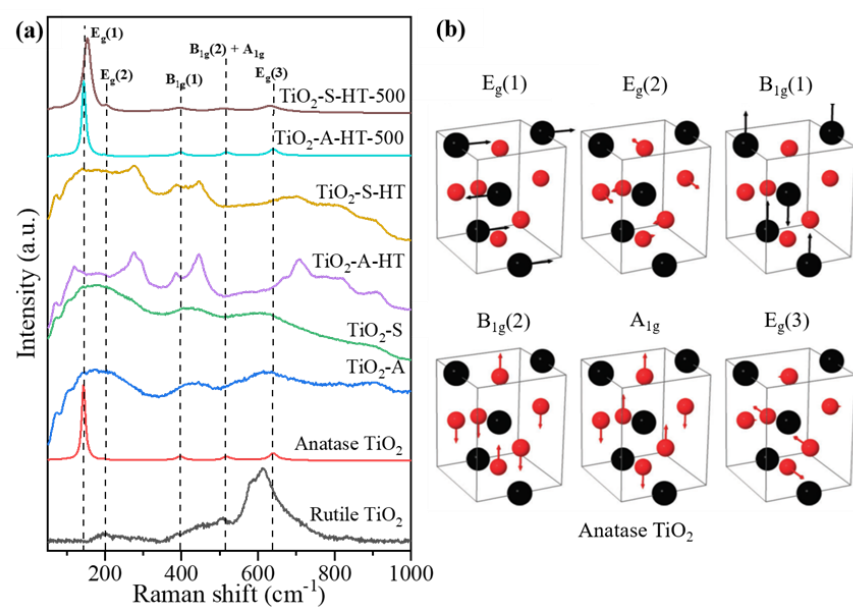

Figure 2. (a) Raman spectra of standard anatase (RRUFF ID: R070582) and rutile (RRUFF ID: R060745), $\mathrm{TiO}_{2}-\mathrm{A}, \mathrm{TiO}_{2}-\mathrm{S}, \mathrm{TiO}_{2}-\mathrm{A}-\mathrm{HT}, \mathrm{TiO}_{2} \mathrm{~S}-\mathrm{HT}$, $\mathrm{TiO}_{2}$-A-HT-500, $\mathrm{TiO}_{2}$-S-HT-500, and (b) schematic of anatase vibrational modes [17]. 
$206.04,396.18,513.34$, and $631.73 \mathrm{~cm}^{-1}$ that assigned to the vibrational modes $\mathrm{E}_{\mathrm{g}}(1), \mathrm{E}_{\mathrm{g}}(2)$, $\mathrm{B}_{1 \mathrm{~g}}(1), \mathrm{B}_{1 \mathrm{~g}}(2)+\mathrm{A}_{1 \mathrm{~g}}$, and $\mathrm{E}_{\mathrm{g}}(3)$, respectively [16]. These peaks represent the vibrational normal modes of anatase as depicted schematically in Figure 2b. Rutile peaks cannot be observed in a calcined sample without deconvolution. In other hands, there are no anatase or rutile peaks can be observed in Raman spectra of uncalcined samples.

To get more structural insights of synthesized $\mathrm{TiO}_{2}$, XRD analysis must be performed.

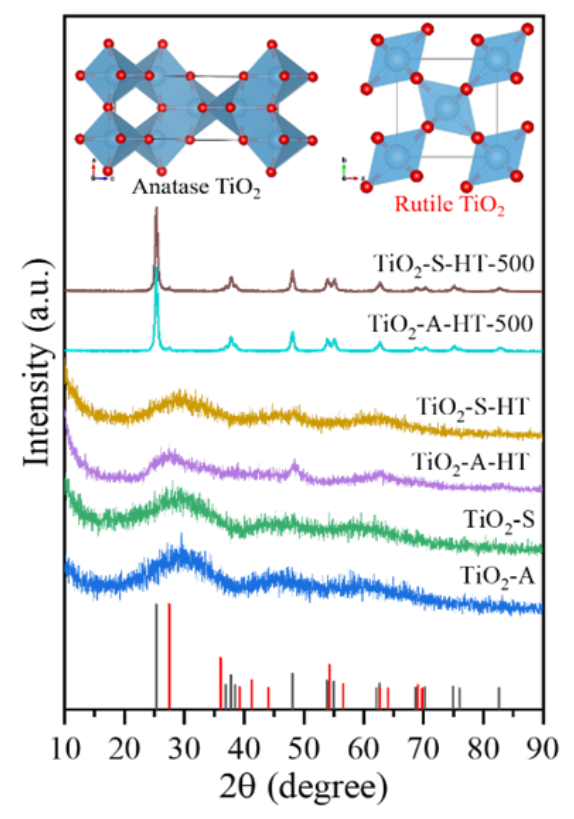

Figure 3. XRD pattern of standard anatase [21] and rutile [22], $\mathrm{TiO}_{2}-\mathrm{A}, \mathrm{TiO}_{2}-\mathrm{S}, \mathrm{TiO}_{2}-\mathrm{A}-\mathrm{HT}$, $\mathrm{TiO}_{2}$-S-HT, $\mathrm{TiO}_{2}$-A-HT-500, and $\mathrm{TiO}_{2}-\mathrm{S}-\mathrm{HT}-500$ with anatase and rutile structures.

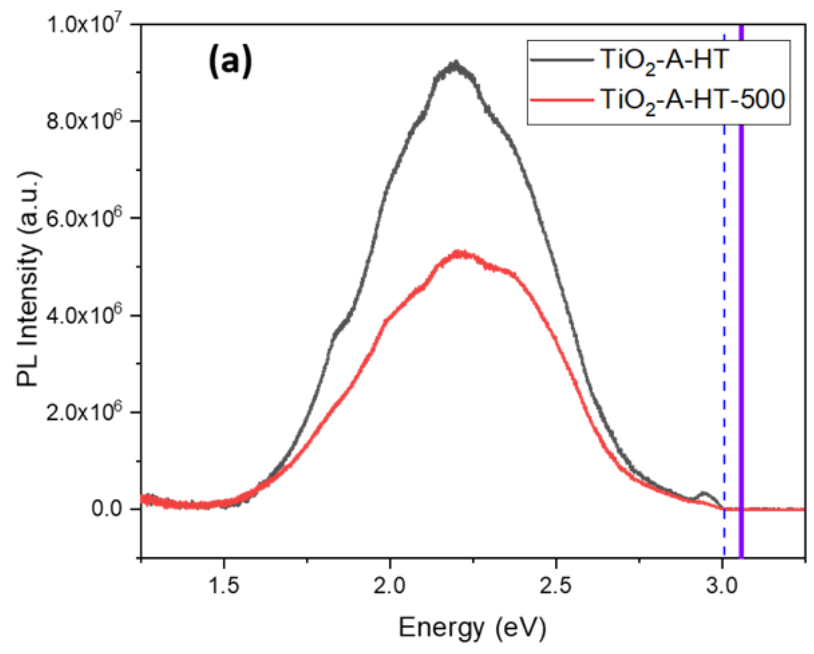

Figure 3 shows the diffractogram of all samples, including the reference standard of rutile and anatase polymorphs. The inset of Figure 3 shows the crystal structure of anatase and rutile. Uncalcined samples $\left(\mathrm{TiO}_{2}-\mathrm{A}, \mathrm{TiO}_{2}-\mathrm{S}, \mathrm{TiO}_{2}\right.$ A-HT, and $\mathrm{TiO}_{2}-\mathrm{S}-\mathrm{HT}$ ) demonstrate similar XRD pattern consists of three broad amorphous peaks at $15.3-35.6^{\circ}, 42.4-52.3^{\circ}$, and 57.2$70.1^{\circ}[18-20]$. The calcined samples show dominant anatase phase with a trace rutile phase. The peaks at 25.3, 36.9, 37.8, 38.7, 48.0, 53.9, $55.1,62.1,62.7,68.7,70.3,75.0,76.1$, and $82.7^{\circ}$ are assigned to the anatase phase [21]. A trace peak at $27.48^{\circ}$ is assigned to the rutile phase [22].

Based on XRD and Raman analysis results, we propose that the structural precursor of anatase phase obtained after calcination has already resided in all uncalcined samples. The structural precursor feature is more pronounced in XRD than in Raman results, represents by three broad amorphous peaks. Structural precursor appears in Raman spectra only as a broad background. Alkaline hydrothermal treatment does not alter much this feature in XRD pattern, only one additional peak appears around $48.05^{\circ}$, represents the anatase phase. This structural precursor feature can be used to indicate where the calcination process will terminate. In this case, the calcination of this material mainly leads to the formation of the anatase phase.

As shown by Raman and XRD measurements, both of $\mathrm{TiO}_{2}-\mathrm{A}-\mathrm{HT}$ and $\mathrm{TiO}_{2}-\mathrm{S}-\mathrm{HT}$ are in amorphous state and turn into anatase crystalline phase after calcination at $500{ }^{\circ} \mathrm{C}\left(\mathrm{TiO}_{2}\right.$ A-HT-500 and $\left.\mathrm{TiO}_{2}-\mathrm{S}-\mathrm{HT}-500\right)$. Amorphous

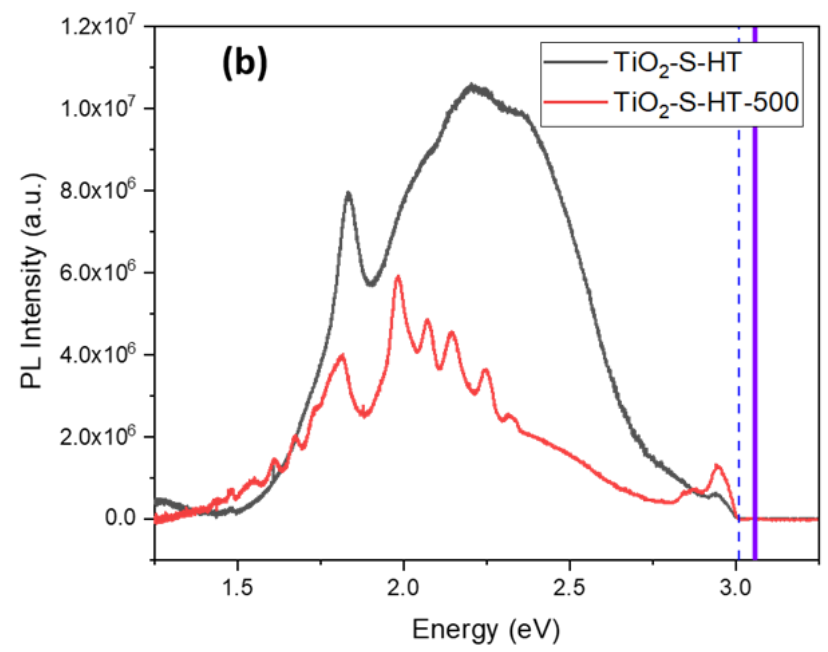

Figure 4. Photoluminescence spectra of synthesized $\mathrm{TiO}_{2}$ particles before and after calcined process for (a) aggregate and (b) spherical bcl particles. 
phase in uncalcined samples provide higher defect density, i.e. surface defects, resulting higher photoluminescence (PL) intensity [23-25]. Figure 4 shows PL spectra of synthesized $\mathrm{TiO}_{2}$ before and after calcination for both aggregate and spherical $b c l$ particles. The dash-line is the limit of long wave pass filter and the straightline represented the excitation laser line at 405 $\mathrm{nm}$. The calcination process transforms amorphous titania phase into anatase crystalline phase decreasing defect density (see Figure 2 and 3). Thus, samples after calcination provide lower PL intensity due to the decrease of defects [23-25]. In $\mathrm{TiO}_{2}$-S-HT-500 samples, we observed many sharp peaks with ordered spacing around $600 \mathrm{~cm}^{-1}$ that corresponds to the phonon coupling of $\mathrm{E}_{\mathrm{g}}(3)$ vibrational normal modes of anatase in electronic transition (see Figure $4 b$ ) [26].

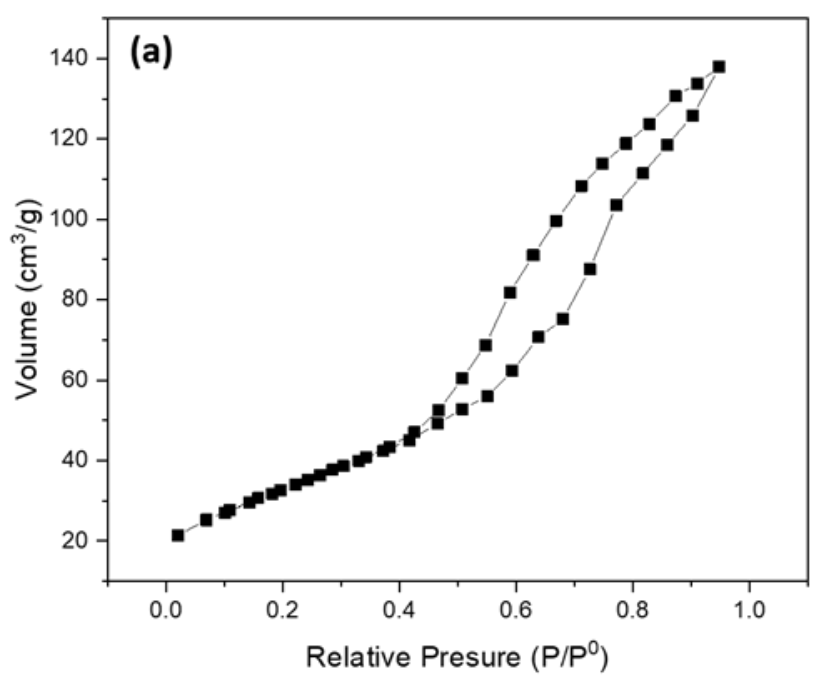

$\mathrm{N}_{2}$ physisorption measurements were conducted to characterize surface properties of synthesized particles, i.e. the specific surface areas, pore volume, and pore diameter. The BET and BJH analysis results are presented in Table 1. In general, the specific surface area of the particles increases after alkaline hydrothermal treatment. For spherical particles, this is attributed to the increase of pore volume and the decrease of pore diameter. On the other hand, this is only attributed to the decrease of pore diameter for aggregated particles. This result is in a good agreement with the SEM analysis where alkaline hydrothermal treatment modifies the surface of particles through swelling and phase segregation resulting lamellar morphology with higher surface area (see Figure 1c and 1d). The calcination process decreases the specific surface area of the parti-

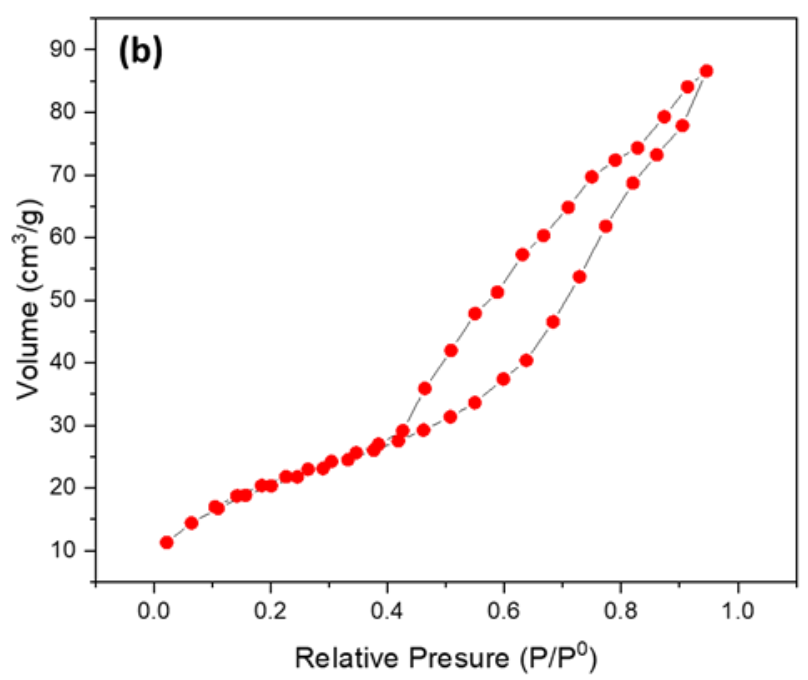

Figure 5. $\mathrm{N}_{2}$ physisorption isotherm of synthesized $\mathrm{TiO}_{2}$ particles (a) $\mathrm{TiO}_{2}$-A-HT-500, and (b) $\mathrm{TiO}_{2}$ S-HT-500.

Table 1. $\mathrm{N}_{2}$ Physisorption Analysis Results of Synthesized $\mathrm{TiO}_{2}$ particles

\begin{tabular}{lccc}
\hline \multicolumn{1}{c}{ Sample } & $\begin{array}{c}\text { Specific surface area } \\
\left(\mathrm{m}^{2} \cdot \mathrm{g}^{-1}\right)^{\mathrm{a}}\end{array}$ & $\begin{array}{c}\text { Pore volume } \\
\left(\mathrm{cm}^{3} \cdot \mathrm{g}^{-1}\right)^{\mathrm{b}}\end{array}$ & $\begin{array}{c}\text { Pore diameter } \\
(\mathrm{nm})^{\mathrm{b}}\end{array}$ \\
\hline $\mathrm{TiO}_{2}$-A & 211 & 0.384 & 7.25 \\
$\mathrm{TiO}_{2}$-A-HT & 253 & 0.292 & 4.62 \\
$\mathrm{TiO}_{2}$-A-HT-500 & 119 & 0.214 & 7.17 \\
$\mathrm{TiO}_{2}-\mathrm{S}$ & 82 & 0.181 & 17.45 \\
$\mathrm{TiO}_{2}-\mathrm{S}-\mathrm{HT}$ & 337 & 0.317 & 7.53 \\
$\mathrm{TiO}_{2}-\mathrm{S}-\mathrm{HT}-500$ & 74 & 0.134 & 7.22 \\
\hline
\end{tabular}

a) Multi-point BET

b) BJH pore size distribution adsorption results 
cles. This is mainly due to the decrease of pore volume for spherical particles and the increase of pore diameter for aggregated particles. Figure $5 \mathrm{a}$ and $5 \mathrm{~b}$ show the $\mathrm{N}_{2}$ physisorption isotherms of $\mathrm{TiO}_{2}$-A-HT-500 and $\mathrm{TiO}_{2}$-S-HT-500 samples, respectively. According to Figure 5a and $5 \mathrm{~b}$, we suggest the synthesized $\mathrm{TiO}_{2}$ particles has a type IVa isotherm where capillary condensation is accompanied by hysteresis that starts to occur for pores larger than $4 \mathrm{~nm}$ in diameter [27]. In this isotherm, we can also observe the characteristic of type H3 hysteresis loop that occurs due to the presence of the nonrigid aggregates of plate-like particles (i.e. particles with lamellar morphology) but also if the pore network consists of macropores which are not completely filled with pore condensate (i.e. continuous v-groove or open channel networks) [27]. Thus, this type of isotherm supports the presence of bcl morphology on the particle surfaces [13].

Although the particles growth mechanism is still obscure, we proposed a general pathway based on bcl silica formation mechanism [13] and this result, to transform oxide particle with any shapes to $b c l$ morphology (see Figure 6). Here, we demonstrated the transformation of aggregated and spherical $\mathrm{TiO}_{2}$ particles to $b c l$ morphology via alkaline hydrothermal route (see Figure 1c and 1d). This process shows a significant increase in specific surface area, especially for spherical particles. The specific surface area for calcined samples, both aggregated and spherical particles, is still higher with re-

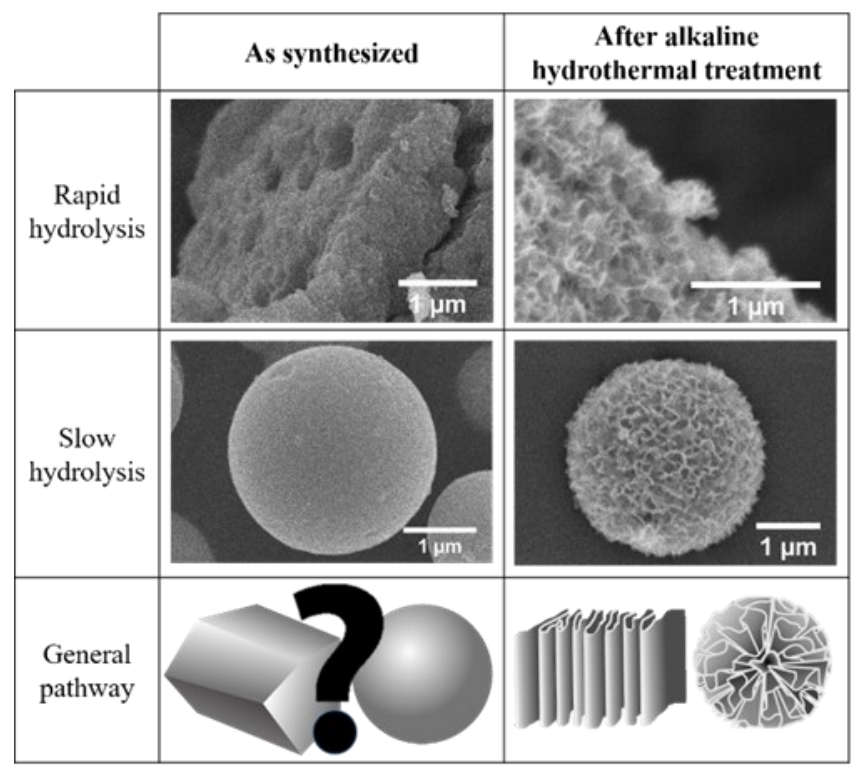

Figure 6. Schematic of $\mathrm{TiO}_{2}$ synthesis route to produce different particle shape with $b c l$ morphology. spect to state-of-the-art $\mathrm{TiO}_{2}$ nanoparticles for photocatalyst, Degussa/Aeroxide P25 $\left(S_{\text {BET }}=\right.$ $\left.35-65 \mathrm{~m}^{2} \mathrm{~g}^{-1}\right)$ [28-30], despite of their microscopic size.

\section{Conclusions}

A simple and effective strategy has been demonstrated to transform aggregated and spherical particles to $b c l$ morphology via alkaline hydrothermal route. We proposed this strategy as a general pathway to transform the particle surface with any shape to have $b c l$ morphology. This strategy succeeded to achieve $\mathrm{TiO}_{2}$ particles with a higher specific surface area than the state-of-the-art $\mathrm{TiO}_{2}$ nanoparticles, Degussa/Aeroxide P25, despite of their microscopic size. This proposed synthesis strategy will open a new perspective in the development of mesoporous materials with open channel pore structure and their applications in a vast variety of fields.

\section{Acknowledgments}

This research was financially supported by ITB Research Grant 2018 as a part of ITB Research and Innovation Program 2018. F. V. Steky acknowledges Directorate General of Higher Education for Bidik Misi scholarship. Muhammad Reza acknowledges Ministry of Education and Culture of Indonesia for the scholarship through Beasiswa Unggulan. D. P. Benu acknowledges Lembaga Pengelola Dana Pendidikan (LPDP) for scholarship support. Authors also acknowledge financial support from Faculty of Mathematics and Natural Sciences, Institut Teknologi Bandung for participation in ICMNS 2018.

\section{References}

[1] Yeh, S.W., Ko, H.H., Chiang, H.M., Chen, Y.L., Lee, J.H., Wen, C.M., Wang, M.C. (2014). Characteristics and Properties of a Novel In Situ Method of Synthesizing Mesoporous $\mathrm{TiO}_{2}$ Nanopowders by a Simple Coprecipitation Process without Adding Surfactant. Journal of Alloys and Compounds, 613: 107-116.

[2] Liu, G., Liu, L., Song, J., Liang, J., Luo, Q., Wang, D. (2014). Visible Light Photocatalytic Activity of $\mathrm{TiO}_{2}$ Nanoparticles Hybridized by Conjugated Derivative of Polybutadiene. Superlattices and Microstructures, 69: 164-174.

[3] Latini, A., Cavallo, C., Aldibaja, F.K., Gozzi, D. (2013). Efficiency Improvement of DSSC Photoanode by Scandium Doping of Mesoporous Titania Beads. J. Phys. Chem. C, 117: 25276-25289. 
[4] Hao, C., Lv, H., Mi, C., Song, Y., Ma, J. (2016). Investigation of Mesoporous NiobiumDoped $\mathrm{TiO}_{2}$ as an Oxygen Evolution Catalyst Support in an SPE Water Electrolyzer. ACS Sustainable Chem. Eng., 4: 746-756.

[5] Jitputti, J., Rattanavoravipa, T., Chuangchote, S., Pavasupree, S., Suzuki, Y., Yoshikawa, S., Qiu, J. (2009). Fabrication of SizeControllable Flower-Like $\mathrm{TiO}_{2}$ and Its Photocatalytic Activity. Journal of the American Ceramic Society, 16: 3-9.

[6] Chen, X., Mao, S.S. (2007). Titanium Dioxide Nanomaterials: Synthesis, Properties, Modifications, and Applications. Chem. Rev., 107: 2891-2959.

[7] Lee, J., Orilall, M.C., Warren, S.C., Kamperman, M., DiSalvo, F.J., Wiesner, U. (2008). Direct Access to Thermally Stable and Highly Crystalline Mesoporous Transition-Metal Oxides with Uniform Pores. Nat. Mater, 7: 222228.

[8] Zhou, H.S., Li, D.L., Hibino, M., Honma, I. (2005). A Self-Ordered, Crystalline-Glass, Mesoporous Nanocomposite for Use as A Lithium-Based Storage Device with Both High Power and High Energy Densities. Angew. Chem. Int. Ed, 44: 797-802.

[9] Alivov, Y., Fan, Z.Y. (2009). A Method for Fabrication of Pyramid-Shaped $\mathrm{TiO}_{2}$ Nanoparticles with a High $\{001\}$ Facet Percentage. J. Phys. Chem. C., 113: 12954-12957.

[10] Nowotny, J., Bak, T., Nowotny, M.K., Sheppard, L.R. (2006). $\mathrm{TiO}_{2}$ Surface Active Sites for Water Splitting. J. Phys. Chem. B, 110: 18492-18495

[11] Bayal, N., Singh, R., Polshettiwar, V. (2017). Nanostructured Silica-Titania Hybrid using Fibrous Nanosilica as Photocatalysts. Chem SusChem, 10: 2182-2191.

[12] Dhiman, M., Chalke, B., Polshettiwar, V. (2015). Efficient Synthesis of Monodisperse Metal (Rh, Ru, Pd) Nanoparticles Supported on Fibrous Nanosilica (KCC-1) for Catalysis. ACS Sustainable Chem. Eng., 3: 3224-3230

[13] Febriyanti, E., Suendo, V., Mukti, R.R., Prasetyo, A., Arifin, A.F., Akbar, M.A., Marsih, I.N. (2016). Further Insight on the Definite Morphology and Formation Mechanism of Mesoporous Silica KCC-1. Langmuir, 32: 5802-5811.

[14] Inaba, R., Fukahori, T., Hamamoto, M., \& Ohno, T. (2006). Synthesis of Nanosized $\mathrm{TiO}_{2}$ Particles in Reverse Micelle Systems and Their Photocatalytic Activity for Degradation of Toluene in Gas Phase. Journal of Molecular Catalysis A: Chemical, 260: 247-254.
[15] Fernández-García, M., Wang, X., Belver, C., Hanson, J.C., Rodriguez, J.A. (2007). Anatase- $\mathrm{TiO}_{2}$ Nanomaterials: Morphological/Size Dependence of the Crystallization and Phase Behavior Phenomena. The Journal of Physical Chemistry C, 111(2): 674-682.

[16] Liu, X-Y., Coville, N.J. (2005). A Raman Study of Titanate Nanotubes. S. Afr. J. Chem., 58: 110-115.

[17] Ohsaka, T., Izumi, F., Fujiki, Y. (1978). Raman Spectrum of Anatase, $\mathrm{TiO}_{2}$. Journal of Raman Spectroscopy, 7(6): 321-324.

[18] Frank, O., Zukalova, M., Laskova, B., Kurti, J., Koltai, J., Kavan, L. (2012). Raman Spectra of Titanium Dioxide (Anatase, Rutile) with Identified Oxygen Isotopes $(16,17,18)$. Phys. Chem. Chem. Phys., 14: 14567-14572.

[19] Li, Y., Qin, Z., Guo, H., Yang, H., Zhang, G., Ji, S., Zeng, T. (2014). Low-Temperature Synthesis of Anatase $\mathrm{TiO} 2$ Nanoparticles with Tunable Surface Charges for Enhancing Photocatalytic Activity. PLoS ONE, 9(12): e114638.

[20] Spada, E.R., Pereira, E.A., Montanhera, M.A., Morais, L.H., Freitas, R.G., Costa, R.G.F., Soares, G.B., Ribeiro, C., de Paula, F.R. (2017). Preparation, Characterization and Application of Phase-Pure Anatase and Rutile $\mathrm{TiO}_{2}$ Nanoparticles by New Green Route. Journal of Materials Science: Materials in Electronics, 28(22): 16932-16938.

[21] Li, Z., Zhu, Y., Wang, J., Guo, Q., Li, J. (2015). Size-Controlled Synthesis of Dispersed Equiaxed Amorphous $\mathrm{TiO}_{2}$ Nanoparticles. Ceramics International, 41(7): 90579062 .

[22] Rezaee, M., Khoie, S.M.M., Liu, K.H. (2011). The Role of Brookite in Mechanical Activation of Anatase-to-Rutile Transformation of Nanocrystalline $\mathrm{TiO}_{2}$ : An XRD and Raman Spectroscopy Investigation. CrystEngComm, 13: 5055-5061.

[23] Howard, C.J., Sabine, T.M., Dickson, F. (1991). Structural and Thermal Parameters for Rutile and Anatase. Acta Crystallographica, Section B, 47: 462-468.

[24] Memesa, M., Lenz, S., Emmerling, S.G.J., Nett, S., Perlich, J., Müller-Buschbaum, P., Gutmann, J.S. (2011). Morphology and Photoluminescence Study of Titania Nanoparticles. Colloid and Polymer Science, 289(8): 943953.

[25] Nakajima, H., Mori, T., Watanabe, M. (2004). Relationship between Photoluminescence Intensity of $\mathrm{TiO}_{2}$ Suspension Containing Ethanol and Its Surface Coverage on $\mathrm{TiO}_{2}$ Surface. Japanese Journal of Applied Physics, 43(6A): 3609-3610. 
[26] Zhu, Y.C., Ding, C.X. (1999). Investigation on the Surface State of $\mathrm{TiO}_{2}$ Ultrafine Particles by Luminescence. Journal of Solid State Chemistry, 145(2): 711-715.

[27] Liu, B., Wen, L., Zhao, X. (2007). The Photoluminescence Spectroscopic Study of Anatase $\mathrm{TiO}_{2}$ Prepared by Magnetron Sputtering. $M a-$ terials Chemistry and Physics, 106(2-3): 350353.

[28] Thommes, M., Kaneko, K., Neimark, A.V., Olivier, J.P., Rodriguez-Reinoso, F., Rouquerol, J., Sing, K.S.W. (2015). Physisoption of Gases, with Special Reference to the Evaluation of Surface Area and Pore Size Distribution (IUPAC Technical Report). Pure and Applied Chemistry, 87(9-10):1-19.
[29] Evonik Resource Efficiency GmbH. (2018, January). AEROXIDE ${ }^{\circledR} \mathrm{TiO}_{2}$ P25: Hydrophilic Fumed Titanium Dioxide. Product Information. Available at https://productsre.evonik.com/www2/uploads/productfinder/A EROXIDE-TiO2-P-25-EN.pdf (Retrieved March 26, 2019); p. 1.

[30] Schmidt, C. M., Weitz, E., Geiger, F. M. (2006). Interaction of the Indoor Air Pollutant Acetone with Degussa P25 $\mathrm{TiO}_{2}$ Studied by Chemical Ionization Mass Spectrometry. Langmuir, 22(23): 9642-9650.

[31] Suttiponparnit, K., Jiang, J., Sahu, M., Suvachittanont, S., Charinpanitkul, T., Biswas, P. (2011). Role of Surface Area, Primary Particle Size, and Crystal Phase on Titanium Dioxide Nanoparticle Dispersion Properties. Nanoscale Research Letters, 6: 27-35 